\title{
Prevention of tumor growth by photo- and X-ray activation of tunsgen cluster complex and its conjugate with DNA molecules
}

\author{
Natalia A. Sitnikova \\ RICEL - Branch of ICG SB RAS \\ Novosibirsk, Russia \\ Anastasiya O. Solovieva \\ RICEL - Branch of ICG SB RAS \\ Novosibirsk, Russia \\ Tatiana N. Pozmogova \\ RICEL - Branch of ICG SB \\ RASNovosibirsk, Russia
}

\author{
Yuri A. Vorotnikov \\ RICEL - Branch of ICG SB RAS \\ NIIC SB RAS \\ Novosibirsk, Russia
}

Svetlana M. Miroshnichenko

RICEL - Branch of ICG SB RAS

Novosibirsk, Russia

\author{
Michael A. Shestopalov \\ RICEL - Branch of ICG SB RAS \\ NIIC SB RAS \\ Novosibirsk, Russia \\ Kushnarenko O. Andrey \\ RICEL- Branch of ICG SB RAS \\ Novosibirsk, Russia
}

\begin{abstract}
Photodynamic therapy (PDT) is one of the most promising methods of treating cancer, although it has it's limitations due to applying visible light sources with limited exposure depth. This allows the method to be used only for superficial tumors treatment and can damage healthy cells as well. To increase the efficiency of the method for treatment of deep lying tumors, it is possible to use other radiation sources, for example, $x$-rays. Thereby search and development of $x$-ray activated photosensitizers is relevant at the moment. In this work a tungsten (W6 $\mathbf{W}_{8}$ ) cluster complex was used as photo- and $\mathrm{x}$-ray- sensitizer and its conjugate with DNA ( $\mathrm{W}_{6} \mathrm{I}_{8} \mathrm{DNA}$ ) as targeting molecules to eliminate Krebs-2 tumor cells and prevent tumor development in vivo.
\end{abstract}

Key words - oncology; Krebs-2; photodinamic therapy; X-ray; tunsgen claster complex; DNA moleculs; cancer treatment

\section{Introduction}

Oncological diseases are widespread in the world and causing a large number of deaths. Well-known treatment methods of cancer such as surgery, radiation therapy and chemotherapy are efficient in some way, but do not prevent relapse of tumors. Photodynamic therapy (PDT) is new and one of the most promising methods of cancer treatment. It is based on an ability of photosensitizers to be activated by specific wavelength and produce singlet forms of oxygen that are known for its cytotoxic effect. Visible light sources are used for photosensitizer activation, but it can be applied only to superficial tumors. To increase the efficiency of the method, it is possible to use other radiation sources, for example, $x$-rays that can penetrate deep tissues. Chen and colleges have already created x-ray activated nanoparticles, but it requires high irradiation dose [1]. It was detected that certain tungsten cluster complex has an ability to be activated by light and x-ray and produce reactive oxygen species (ROS) [2], [3]. Such properties allow it to be possible photo- and x-ray sensitizer. In this study, we also used tungsten cluster complex conjugated with DNA molecules for the better targeting of induced cancer cells. It has been shown that certain type of tumor cells absorb DNA molecules more efficiently than other cancer cells and normal cells [3].

The main goal for our work is to exanimate tungsten cluster complex and its conjugate with DNA for photodynamic and $\mathrm{x}$ ray dynamic abilities on in vivo Krebs-2 tumor cells.

\section{Materials and Methods}

Tungsten cluster complex $\left(\mathrm{Bu}_{4} \mathrm{~N}\right)_{2}\left[\left\{\mathrm{~W}_{6} \mathrm{I}_{8}\right\}\left(\mathrm{NO}_{3}\right)_{6}\right]$ was synthesized in Laboratory of Bioactive Inorganic Compounds (Nikolaev Institute of Inorganic Chemistry SB RAS) [4]. Its conjugation with DNA molecules was carried out by intercalating the cluster into double-stranded DNA using the DNA denaturation step.

Krebs-2 mouse carcinoma line cells were used in current study. Cells were cultivated with $\left(\mathrm{W}_{6} \mathrm{I}_{8}\right)$ and $\left(\mathrm{W}_{6} \mathrm{I}_{8} \mathrm{DNA}\right)$ for 2 hours in standard culture conditions $\left(37^{\circ} \mathrm{C}, 5 \% \mathrm{CO}_{2}\right)$. After that, cells were irradiated with $500 \mathrm{~W}$ halogen lamp for 30 minutes or with $\mathrm{x}$-ray source. The resulting radiation dose was $20 \mathrm{~J} / \mathrm{cm}-2$ (light) and 120Gr (x-ray).

$\mathrm{CBA} / \mathrm{Lac}$ mice 4 month old were vaccinated with irradiated cancer Krebs- 2 cells intramuscularly $\left(200 * 10^{3}\right.$ cells). The next 42 days dynamic of tumor growth was observed. On 42 d day all mice with tumors were decapitated and tumors were collected for histological analyze. Control group consisted with mice that received cells with no exposure to light or X-ray. All the animal studies conform to standards and a protocol approved by the Institutional Animal Care and Use Committee.

Statistic analyze was carried out by Statistic 8. Quantitative data were expressed as mean \pm s.e.m. A nonparametric MannWhitney U-test was used for comparing the treatment groups and the control groups. $\mathrm{P}<0.05$ was considered statistically significant.

\section{Results}

Solid tumors Krebs-2 appear palpable on $7-11^{\text {th }}$ day after injection in $100 \%$ mice in control group. Other control groups, 
where cells were previously irradiated with light or x-ray, show no difference in growth dynamic and final size of tumors.

Preliminary incubation of Krebs-2 cells with tungsten cluster complex $\left(\mathrm{Bu}_{4} \mathrm{~N}\right)_{2}\left[\left\{\mathrm{~W}_{6} \mathrm{I}_{8}\right\}\left(\mathrm{NO}_{3}\right)_{6}\right]$ also did not affect tumor growth in mice itself (control $\mathrm{W}_{6} \mathrm{I}_{8}$ ). However, irradiation of these cells with X-ray led to the latter appearance of tumors and smaller sizes in comparison with both control $\mathrm{W}_{6} \mathrm{I}_{8}$ and light $\mathrm{W}_{6} \mathrm{I}_{8}$ (Fig. 1).

Incubation of Krebs-2 cells with tungsten cluster complex $(\mathrm{Bu} 4 \mathrm{~N})_{2}\left[\left\{\mathrm{~W}_{6} \mathrm{I}_{8}\right\}\left(\mathrm{NO}_{3}\right)_{6}\right]$ conjugate with DNA molecules did not affect tumor growth in mice without activation of cluster. However, irradiation of these cells with $\mathrm{x}$-ray, as in the case with just $\mathrm{W}_{6} \mathrm{I}_{8}$, led to the latter appearance of tumors and smaller sizes in comparison with both control $\mathrm{W}_{6} \mathrm{I}_{8}$-DNA and light $\mathrm{W}_{6} \mathrm{I}_{8}-$ DNA. In some mice in this group tumors did not appeared at all (Fig. 1). Incubation of Krebs-2 cells with tungsten cluster complex $\left(\mathrm{Bu}_{4} \mathrm{~N}\right)_{2}\left[\left\{\mathrm{~W}_{6} \mathrm{I}_{8}\right\}\left(\mathrm{NO}_{3}\right)_{6}\right]$ and with its conjugate with DNA molecules has no differences between sizes of tumors induced by injections of such cells both without irradiation and with light or $\mathrm{x}$-ray irradiation.

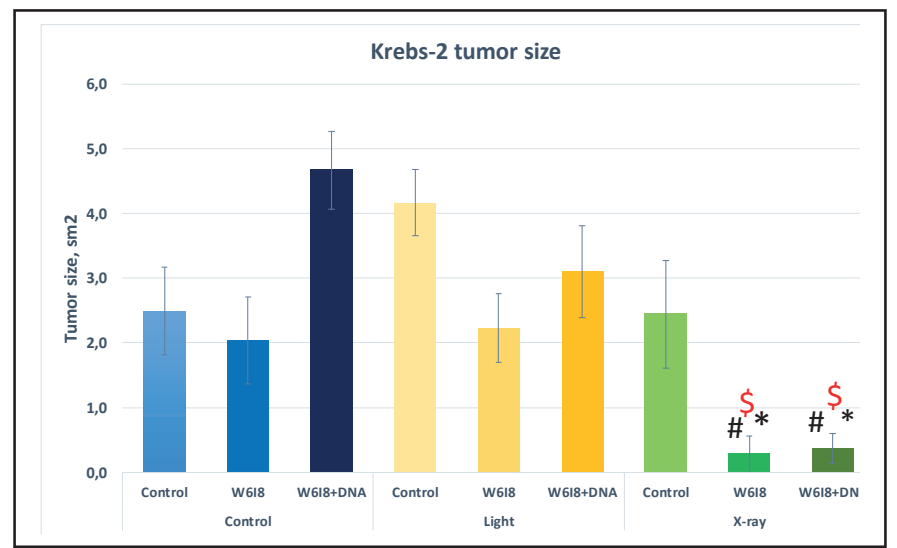

Fig. 1. Krebs-2 tumor size $\left(\mathrm{sm}^{2}\right)$ after 42 days of cultivation in mice CBA/Lac 4-6 month old. Krebs-2 cells were previously incubated with (W6I8) and (W6I8DNA) for 2 hours in standard culture conditions $\left(37^{\circ} \mathrm{C}, 5 \% \mathrm{CO} 2\right)$. After that, cells were irradiated with $500 \mathrm{~W}$ halogen lamp for 30 minutes or with $\mathrm{x}$ ray source. The resulting radiation dose was $20 \mathrm{~J} / \mathrm{cm}-2$ (light) and $120 \mathrm{Gr}$ (xray). Group with tumors from cells with no exposure to light or $\mathrm{x}$-ray was control group. Quantitative data were expressed as mean \pm s.e.m. $N=6$. A nonparametric Mann-Uitny test was used for comparing the treatment groups and the control groups.

(* - p <0.05) - X-ray compared to light, (\# - p <0.05) - X-ray compared to control, $(\$-\mathrm{p}<0.05)-(\mathrm{W} 6 \mathrm{I} 8)$ and (W6I8DNA) compared with control in $\mathrm{X}$ ray group.

\section{Conclusion}

Therefore we found out that Tungsten cluster complex $\left(\mathrm{Bu}_{4} \mathrm{~N}\right)_{2}\left[\left\{\mathrm{~W}_{6} \mathrm{I}_{8}\right\}\left(\mathrm{NO}_{3}\right)_{6}\right]$ and its conjugate with DNA ( $\mathrm{W}_{6} \mathrm{I}_{8} \mathrm{DNA}$ ) can be activated with $\mathrm{x}$-ray which leads to elimination of Krebs- 2 cells. Considering, that $\mathrm{W}_{6} \mathrm{I}_{8}$ itself has an ability to produce ROS, than this part of conjugate is responsible for elimination. Irradiated Krebs-2 cells intramuscular injection reduce tumor growth or leads to its absence. Meanwhile in control group Krebs-2 tumors reached considerable size. As we know that cancer initiating cells absorb DNA molecules more efficiently [3], we can assume that this type of tumor cells was eliminated specifically and tumor cells suspension was not capable to induce tumor growth or the growth was not so fast and efficient.

Furthermore, it was revealed that tungsten cluster complexes $\left(\mathrm{Bu}_{4} \mathrm{~N}\right)_{2}\left[\left\{\mathrm{~W}_{6} \mathrm{I}_{8}\right\}\left(\mathrm{NO}_{3}\right)_{6}\right]$ have no effect on cells viability, which is one of the essential properties for photo- and X-ray sensitizers. Consequently, X-ray irradiation can be an activator of particular photosensitizers, since there is no toxic effect on living cells on its own. The use of X-rays will reduce the likelihood of death of normal cells and increase the depth of the location of tumors that can be removed by this method. However, to evaluate the effectiveness of X-ray irradiation in photodynamic therapy, further studies are necessary.

\section{ACKNOWLEDGMENT}

This research is supported by RFBR № 18-315-00235.

\section{REFERENCES}

[1] H. Chen, G. Wang, Y. Chuang et al. "Nanoscintillator-mediated X-ray inducible photodynamic therapy for in vivo cancer treatment," Nano Lett., vol. 15, no. 4, pp. 2249-2256, 2015.

[2] E. V. Svezhentseva, Y. A. Vorotnikov et al. "From photoinduced to dark cytotoxicity through an octahedral cluster hydrolysis," Chem. - A Eur. J., vol. 24, no. 68, pp. 17915-17920, 2018.

[3] D. V. Evtushok, A. R. Melnikov, N. A. Vorotnikova et al. "A comparative study of optical properties and X-ray induced luminescence of octahedral molybdenum and tungsten cluster complexes," Dalt. Trans., vol. 46, no. 35, pp. 11738-11747, 2017.

[4] E. V. Dolgova, E. A. Potter, A. S. Proskurina et al. "Properties of internalization factors contributing to the uptake of extracellular DNA into tumor-initiating stem cells of mouse Krebs-2 cell line," Stem Cell Res. Ther., vol. 7, no. 1, pp. 1-16, 2016. 